Die ganze Art der langsamen Entstehung der blauen Farbe, die Bildung einiger blauen Pünctchen und das Weitergreifen von diesen Centralstellen aus, spricht für die Schimmelbildung, wie sie überall sich zeigt.

Die Schimmelbildung auf Rahm oder Milch ist übrigens sehr allgemein verbreitet, und wichtig wäre es $\mathrm{zu}$ erfahren, ob diese gewöhnlich ungefärbten Schimmelpilze gleicher Art sind, wie die hier blau getärbten, oder ob eine besondere Art hier auftrete. Dies müssen weitere Untersuchungen ergeben.

Schon oben wurde erwähnt, dass die Aenderung des Futters der Kühe hier keinen Finfluss nachweislich gezeigt habe, jedoch wurde der frische Klee, während dessen Verfütterung zuerst dic blaue Färbung der Milch eintrat, noch auf abnorme Bestandtheile geprüft.

Dieser Klee war von schön grüner Farbe, hier und da waren kleinere oder grössere rostfarbene Flecken. Der Aschengehalt und die Zusammensetzung derselben waren ganz wic gewöhnlich, namentlich war keine auffällige Menge Eisen vorhanden.

Der wässerige Auszug der Pflanze, analog der Bereitung des Indigo mit Kalkwasser versetzt u. s. w. behandelt, zeigte nicht die geringste blaue Färbung, welche auf einen derartigen Farbstoff hätte deuten lassen.

\title{
Ueber den Gehalt von Schwefelwasserstoffgas im Tabacksrauche;
}

von

Dr. X. Landorer in Athen.

Mein verehrter Freund Prof. Dr. Vogel hat sich mit vieler Mühe und Ausdaner mit der Untersuchung der Bestandtheile des Tabacksrauches beschäftigt und in demselben nicht nur Schwefel-, sondern auch Cyangehalt gefunden, eine Entdeckung, die mich sehr interessirte, und deren Untersuchung ich in dem Lande, wo die ganze 
Welt Taback raucht, der Belehrung wegen wiederholen wollte.

Die in Griechenland vorkommenden und zum Rauchen gebräuchlichen Tabackssorten sind alle rein, ohne Beize, Sauce und Gährung werden dieselben verwendet. Wie das Blatt von der Pflanze kommt und auf Schnüre gereiht an der Sonne getrocknet wird, so bleibt es. Die Blätter in Büschel zusammengebunden, werden nun in hänfene Säcke so fest als möglich eingetreten und mit Lasten beschwert, worauf die Ballen als orientalischer, griechischer oder levantinischer Taback in den Handel kommen. Der griechische oder levantinische Taback ist im Allgemeinen gut, jedoch giebt es eine Menge Sorten, die sich durch ihre Bestandtheile, ihr Aroma, welches wohl nicht von dem Nicotingehalte, sondern von einem eigenthiumlichen flüchtigen Stoffe, einem Tabacks-Aroma, einem itherischen Oele sui generis abhängt - von einander unterscheiden. Wegen dieses Tabacks-Oeles oder Aromas unterwarf ich einige Okken Taback einer Destillation mit Wasser und erhielt ein Destillat, das einen krautartigen, dem Taback ganz fremden Geruch besass, auf welchem jedoch einige Tropfen eines tief-dunkelgelb gefärbten Oeles schwammen. Dieses Oel hatte, in der Hand verrieben, den eigenthümlichen penetranten Tabacksgeruch im höchsten Grade. Durch Verdampfen von ein Paar Tropfen desselben auf einem warmen Eisenblech füllte sich ein grosses Zimmer mit dem Geruch nach Taback, gleich als liätte man in demselben grosse Mengen Taback zur Trockne ausgebreitet. Dieses Tabacks-Oel ist ammoniakhaltig, denn bei Anniherung eines init Salzsäure befeuch. teten Glasstabes entwickelten sich aus demselben starke weisse Nebel, die der Bildung von Chlorammonium angehörten. *)

Es wäre wichtig, wenn dieses Oel genau untersucht würde, wozu jedoch wenigstens $30-50$ Pfund Taback 
verwendet werden müssten, um daraus ungefähr 1 Quentchen Oleum Nicotianae Tabacum aethereum zu erhalten.

Der Taback wird in Griechenland theils aus langen Pfeifen, grösstentheils jedoch als Papier-Cigarren und auch in den sogenannten Angellides geraucht. Bei den letzteren wird der Tabacksrauch mittelst eines langen elastischen Rohres durch das in einem Gefässe sich befindende Wasser gezogen, wodurch sich natürlich der Tabacksrauch abküblt und zu gleicher $Z$ cit von seinen brenzlichen Theilen befreit wird, also kalt in den Mund gelangt. Dass sich dieser gereinigte Tabacksrauch von dem unmittelbar aus den Pfeifen eingezogenen wesentlich unterscheidet, ist leicht einzusehen. Prof. Vogel erwähnt eines Blausiiure- und eines Schwefelwasserstoffgehalts in dem Tabacksrauch.

Um nun in dem griechischen Taback den Schwefelgehalt zu ermitteln, verschaffte ich mir eine oben erwähnte Angellis. Es ist sicher, dass sich in dem Wasser, wodurch der Tabacksdampf geht, alle löslichen Bestandtheile finden. So gereinigt untersuchte ich dasselbe auf den Schwefel- und Cyangehalt. Dieses mit allen Producten der trocknen Destillation gesïtigte Wasser hatte einen eigenthümlichen, brenzlichen, tabacksähnlichen, ammoniakalischen Geruch, eine bräunliche Farbe und einen eben solchen unangenehmen, sehr bittern Geschmack. Nach Umrühren eines mit Salzsüure befeuchteten Glasstabes entwickelten sich aus demsclben weisse Dämpfe und geröthetes Lackmuspapier wurde wieder gebläut, so dass über den Ammoniakgehalt dieses Wassers kein Zweifel obwalten konnte.

Eine grosse Quantität dieses Wassers mit Prussidnatriumlösung versetzt, erlitt nicht die geringste Veränderung, so dass sich durch dieses sonst so empfindliche Reagens auf Schwefelwasserstoffgehalt kein solcher entdecken liess.

Eine andere Quantität dieses Tabackswassers wurde mit Bleiacetatlösung, eine dritte mit Kupfervitriollösung 
und auch mit Chlorarseniklösung vermischt, und liess nicht den geringsten Schwefelgehalt erkennen, weshalb ich fest überzeugt bin, dass in diesem Tabackswasser sich kein Schwefel befand.

In Betreff des Cyangehalts hatte ich das Wasser durch vorsichtiges Eindampfen so viel als möglich zu concentriren versucht und sodann dasselbe mit schwefelsaurem Eisenoxyduloxyd versetzt. Nach einer Stunde zeigte sich eine sonderbare Erscheinung, die ich weiter zu untersuchen nicht im Stande war. Im Anfange blieb die Flüssigkeit hell, es bildete sich kein Niederschlag, nach $1 / 2$ Stunde begann die Flüssigkeit unter dem Einflusse der Luft, nachdem sie mit dem Eisensalze versetzt war, sich zu röthen, und diese Röthung steigerte sich, bis sie die Farbe sehr verdünnter Rhodaneisenlösung angenommen hatte, wobei sich kein Niederschlag absetzte. Verschiedene Versuche, die ich zur Bestätigung anstellte, ob diese Färbung einer Rhodanverbindung angehöre oder nicht, ïberzeugten mich, dass dieselbe nicht von Schwefelcyan herrühre, sondern von einer andern brenzlichen Substanz, die sich aus dem Taback gebildet hatte. Um nun den Schwefelgehalt im Rauche des griechischen Tabacks zu ermitteln, zog ich den Rauch durch ein kleines Angellis, worin sich Prussidnatriumlösung mit Ammoniak versetzt, gelöst befand. Obwohl ich mehrere Cigarren rauchen liess und mich sehr bemühte, den Schwefelgehalt durch die so charakteristische Färbung des Prussidnatriums zu constatiren, so gelang es mir nicht, denselben aufzufinden, so dass ich die Ueberzeugung habe, dass sich in diesem untersuchten griechischen Taback kein Schwefel befindet.

Um den Cyangehalt im Tabacksrauche zu ermitteln, befolgte ich Dr. Vogel's Methode der Durchleitung des Tabacksrauches durch eine Lösung von kaustischem Kali. Diese Kalilösung, worin sich das Cyan als Cyankalium finden sollte, wurde mittelst Eisenoxyduloxyds auf Cyan 
untersucht, jedoch gelang ez mir nicht, auch nur eine Spur Cyaneisen zu erbalten.

In dem Tabackssafte, der sich in den langen Pfeifen der Orientalen sammelt, sind alle brenzlichen und schädlichen Stoffe des Tabacksrauches enthalten. Derselbe ist im Oriente schon oft Uraache zu tödtlichen Vergiftungen gewesen, indem die Leute diesem Tabackssafte specifische Wirkungen gegen exanthematische Hautleiden zuschreiben. Dass derselbe solche Eigenschaften besitzt ist wohl anzunehmen, indem chronische bösartige Hautkrankheiten, Ausschläge der Leprosen dadurch zum Verschwinden gebracht und topische Leiden geheilt werden. Es fehlt jedoch nicht an Beispielen, dass nach Anwendung dieses Tabackssaftes sich andere gefährliche Symptome einstellten, dass der Patient von Krämpfen befallen wurde und mit dem Tode rang. Erst vor kurzer Zeit starb auf einem Dorfe in der Nähe cin Kind unter heftigen Krämpfen in Folge der Anwendung des Tabackssaftes, den die unvernünftigen Eltern demselben auf die wunden Stellen von Intestrigo aufgeschmiert hatten. Demnach dürfte der Tabackssaft oder die Producte der trocknen Destillation desselben zu den heftigen Giften gehören, ohne dass in denselben Cyanverbindungen vorhanden wären.

Aus diesen angeführten Versuchen ergiebt sich, dass in dem Rauche des griechischen Tabacks weder Schwefel noch Cyan aufzufinden war, eine Erscheinung, die gewiss dem Taback selbst zuzuschreiben ist.

\section{Ueber eine unfruchtbare Kleierde im Olden- burgischen; von Ed. Harms.}

In dem nördlichen Theile des Herzogthums Oldenburg, welcher zwischeen der Weser und der Jahde liegt, Arch. d. Pharm. CLIUI. Bds. 1.Hft. 